\title{
Procyclicality and path dependence of sovereign credit ratings: The example of Europe
}

Citation for published version (APA):

Freitag, L. (2014). Procyclicality and path dependence of sovereign credit ratings: The example of Europe. Maastricht University, Graduate School of Business and Economics. GSBE Research Memoranda No. 020 https://doi.org/10.26481/umagsb.2014020

Document status and date:

Published: 01/01/2014

DOI:

10.26481/umagsb.2014020

Document Version:

Publisher's PDF, also known as Version of record

\section{Please check the document version of this publication:}

- A submitted manuscript is the version of the article upon submission and before peer-review. There can be important differences between the submitted version and the official published version of record.

People interested in the research are advised to contact the author for the final version of the publication, or visit the DOI to the publisher's website.

- The final author version and the galley proof are versions of the publication after peer review.

- The final published version features the final layout of the paper including the volume, issue and page numbers.

Link to publication

\footnotetext{
General rights rights.

- You may freely distribute the URL identifying the publication in the public portal. please follow below link for the End User Agreement:

www.umlib.nl/taverne-license

Take down policy

If you believe that this document breaches copyright please contact us at:

repository@maastrichtuniversity.nl

providing details and we will investigate your claim.
}

Copyright and moral rights for the publications made accessible in the public portal are retained by the authors and/or other copyright owners and it is a condition of accessing publications that users recognise and abide by the legal requirements associated with these

- Users may download and print one copy of any publication from the public portal for the purpose of private study or research.

- You may not further distribute the material or use it for any profit-making activity or commercial gain

If the publication is distributed under the terms of Article $25 \mathrm{fa}$ of the Dutch Copyright Act, indicated by the "Taverne" license above, 


\section{Maastricht University}

Lennart Freitag

Procyclicality and Path

Dependence of Sovereign Credit Ratings: The example of Europe

$\mathrm{RM} / 14 / 020$

\section{GSBE}

Maastricht University School of Business and Economics

Graduate School of Business and Economics

P.O Box 616

NL- 6200 MD Maastricht

The Netherlands 


\title{
Procyclicality and Path Dependence of Sovereign Credit Ratings:
}

\author{
The example of Europe
}

\author{
Lennart Freitag *
}

May 19, 2014

\begin{abstract}
This paper investigates empirically the behavior of Credit Rating Agencies (CRAs) when assessing sovereign solvency for European countries. Using Probit regressions I find that even after controlling for macroeconomic factors, CRAs take the business cycle into account. Also, there is a clear case of path dependence in sovereign ratings. Additionally, it turns out that there seems to be a discrepancy between upgrades and downgrades. These results are robust to a number of different specifications.
\end{abstract}

JEL Classification: G15, G24

Keywords: rating agency, sovereign debt crisis, sovereign credit rating, procyclical lending

*Department of Economics, Maastricht University, PO box 616, 6200 MD Maastricht, the Netherlands, l.freitag@maastrichtuniversity.nl

Lennart Freitag wants to thank Bertrand Candelon, Elena Dumitrescu, Oana Floroiu, and Simone Vermeend. 


\section{Introduction}

This paper investigates whether Credit Rating Agencies (CRAs) assign ratings to European sovereigns in a procyclical manner as well as whether or not ratings are path dependent. For the former that is whether ratings depend on the business cycle, for the latter whether rating history is a significant factor in determining current ratings. So far, the literature on credit ratings for emerging countries is abundant, however the literature on developed countries is sparse and the topic of this procyclical behavior or dynamic components in ratings for developed countries has not been investigated. Credit rating agencies (CRAs) and their actions are playing an increasingly significant role, not only in financial markets but also by affecting decisions of policymakers. Since the global financial crisis that started in 2007 and the recent Euro-area crisis, the actions of CRAs have come again under scrutiny, not only by the public but also by academics, see for example Arezki et al. (2011) or Baum et al. (2013). Therefore, CRAs and their behavior have become an important topic for discussion not only between market participants but also for the general public.

The first characteristic of sovereign ratings analyzed in this paper is the procyclical behavior. For the purpose of this paper, ratings are considered to move procyclically if they are positively correlated with economic or credit cycle fluctuations. In particular, procyclicality relates to the sensitivity of ratings towards these cycles and their conditionality upon macroeconomic fundamentals. However, this directly collides with rating through the cycle (see Altman and Rijken 2004), which implies that ratings are based upon issuer or issue specific characteristics and are independent from the economic cycle.

When CRAs assign a long term sovereign rating, they formulate their opinion on the creditworthiness of a sovereign and they express this opinion by using an established and defined ranking system of rating categories. In doing so, CRAs do not necessarily need to calculate an absolute measure of default, but rather to assess the riskiness of default of an issue or an issuer through time. That is exactly why we may observe that default definitions vary among CRAs. In particular, Standard and Poor's Ratings Services (S\&P) treats payment defaults on financial obligations, certain distressed exchanges and breaches of imputed payment promises as a default. Moody's Investors Service's (Moody's) definition of debt default constitutes various events, including missed or delayed disbursements, bankruptcy filings or legal receiverships, distressed exchanges and a changes in the payment terms imposed by a sovereign. Fitch Ratings (Fitch) distinguishes between restricted default (when an uncured payment default occurs, which does not lead to a formal winding-up procedure or ceasing of business) and default (an uncured payment default which leads to a formal winding-up procedure or ceasing of business). Moreover, other smaller CRAs have their own definitions of default, which may include, but are not limited to, the above elements from the definitions of the three larger CRAs.

One role of CRAs is to provide long term information to investors in order for them to optimize their investment. This information, which is embedded in the rating, should have a long term nature and not just a short or medium term scope. Therefore, long term ratings should be independent of the economic cycle and, by definition, are not supposed to vary in a procyclical manner. Looking at methodological documents and criteria articles across CRAs, one can easily identify that CRAs indeed claim that they rate through the cycle. A straightforward way to have a view of how ratings move vis-à-vis the economic cycle, is to look at widely used metrics, such as transition matrices and rating statistics and examine rating movements conditional upon the cycles. For example, we can review European sovereign ratings of the three larger CRAs, regarding upgrades and downgrades for the period 1.1.2006-31.12.2008 and 1.1.2009-31.12.2011 (constituting a growth and a downturn period respectively).

Through these statistics on sovereign ratings, one can see whether or not ratings tend to show higher 
Table 1: EU 27 ratings 2006-2011

\begin{tabular}{ccccccc}
\hline Agency & \multicolumn{2}{c}{ S \& P } & \multicolumn{2}{c}{ Moody's } & \multicolumn{2}{c}{ Fitch } \\
\hline Date & & & & & & \\
& $2006-2008$ & $2009-2011$ & $2006-2008$ & $2009-2011$ & $2006-2008$ & $2009-2011$ \\
\hline Upgrades & 5 & 4 & 10 & 1 & 9 & 4 \\
\hline downgrades & 9 & 25 & 3 & 26 & 8 & 19 \\
\hline
\end{tabular}

occurrence of downgrades during an economic downturn or higher occurrence of upgrades during an economic growth. Indeed taking a look at table 1, for the period covering the years 2006 to 2008 , there were more upgrades than downgrades for all the three large CRAs. During the sovereign crisis period (2009-2011), downgrades occurred relatively more frequently. For the three CRAs the number of downgrades were more than three times greater than the number of upgrades.

However, even if tools like descriptive statistics and transition matrices can provide an initial view on whether or not ratings move procyclically across different periods, they fail to prove that ratings are indeed assigned in a procyclical manner. In this study it is investigated whether CRAs actually assign investment grades for sovereign solvency procyclically.

The second characteristic of sovereign rating that is analyzed in this paper is that of path dependence. This means that current rating are depending on past ratings. This phenomenon is closely connected to procyclicality, but not the same. Procyclicality basically asks the question whether or not ratings are better than expected when controlling for macroeconomic characteristics economic boom time vice versa. Therefore, the idea behind procyclicality is that analysts might get overly optimistic when good news from the economy are pouring in. Conversely, path dependence simply means that the current rating is dependent upon the previous rating. This would imply for CRAs that rating level are very sluggish, that is only move very slowly compared to the information released about the economic conditions in the sovereign that is rated.

To understand the exact implication of this research question one has to be aware of the actual role CRAs play in the current financial system. The Basel agreements have been the cornerstones of the current financial architecture since the beginning of the nineties. These agreements regulate the amount of capital banks have to retain for an investment of a given riskiness. One possibility to assess the risk of an individual asset is to rely on the judgment of CRAs. The big three agencies (S \& P, Moody's and Fitch) work with an issuer-pays model. This means that the banks do not pay for using the ratings and it implies that from a business perspective it is more efficient for banks to use ratings provided by the CRAs instead of maintaining an own risk assessment division. This makes the CRAs dominant entities in the risk assessment business. Furthermore, a change in the rating of an asset might require banks to increase or decrease the amount of capital held (depending on whether it is an upgrade or a downgrade). This fact together with their market dominance in risk assessment gives rating-changes the power to move large amount of capital as documented by Gande and Parsley (2010).

In this paper, the research questions are approached with (ordered) probit regressions, since the assumptions underlying this regression model match the nature of the data. I find that no agency is completely consistent in assigning ratings. There is evidence of procyclicality, sluggish rating assignment and country-group based discrimination even after controlling for typical macroeconomic variables. I also find a substantial difference in explanatory power for upgrades and downgrades. To the best of my knowledge there exists no other study which looks into the procyclicality issue from a sovereign debt perspective for developed countries. Furthermore, only a very limited number of studies were conducted 
using mostly developed country data, mainly because these countries were seldom downgraded prior to 2008 .

The question of how the business cycle gets amplified by reckless lending in times of boom and a credit crunch in times of recession has been an issue for a long time. Borio et al. (2001) gives a general overview of the topic. So far there has been numerous proposals for actual reasons of this bank behavior, ranging from the idea that an actual fall in demand for loans is looking like a credit crunch as in Bernanke et al. (1991), who study the 1990-1991 recession in the United States, the idea of institutional memory leading to the deterioration of the skill of bank staff in Berger and Udell (2004), or that it is inherently anchored in the current financial architecture put forward by Lowe (2002). The idea that this cycle could be supported by rating agencies has so far gotten little academical attention despite the strong criticism that the CRAs are facing since 2007. Ferri et al. (1999) investigate the behavior of rating agencies in the Asian financial crisis of 1997 to 1998, and conclude that procyclical behavior can be shown during this crisis. Furthermore Bar-Isaac and Shapiro (2012) show that in a dynamic model quality of ratings correlates negatively with the business cycle, which gives a theoretical foundation to the idea of procyclicality in credit ratings. With this paper I attempt to fill the literature gap on procyclicality for sovereign ratings and extend the literature on developed country sovereign debt ratings.

The rest of the paper is structured as follows. The methodology will be discussed in section 2 , section 3 is devoted to the empirical analysis of the research questions, and section 4 concludes.

\section{Methodology}

\subsection{General Framework}

We start by assuming that there exists a latent process of the form:

$$
Y_{i, t}^{*}=X_{i, t} \beta^{\prime}+E_{i, t}
$$

where $Y_{i, t}^{*}$ is the dependent variable. $X_{i, t}$ is a matrix of regressors, and $E_{i, t}$ represents the errors which are standard i.i.d distributed and independent of the regressors $X_{i, t}$. The actual realization of the left hand side variable $Y_{i, t}^{*}$ is being governed by the rules:

$$
Y_{i, t}= \begin{cases}1 & \text { if } Y_{i, t}^{*}>0 \\ 0 & \text { if } Y_{i, t}^{*} \leq 0\end{cases}
$$

or

$$
Y_{i, t}=\left\{\begin{array}{cl}
0 & \text { if } Y_{i, t}^{*} \geq \alpha_{1} \\
1 & \text { if } \alpha_{1}<Y_{i, t}^{*} \geq \alpha_{2} \\
\vdots & \\
J & \text { if } Y_{i, t}^{*}>\alpha_{J} .
\end{array}\right.
$$

The $\alpha$ 's denote the threshold parameters. The first rule gives rise to a binary regression model and the second rule to a categorical or ordered regression model. The choice of the particular regression method employed depends on the assumptions made on the distribution of $E_{i, t}$. A standard normal distribution 
would indicate the use of a probit regression, whereas a standard logistic one would indicate the use of a logit regression.

I assume that the process described in equation (1) is a good approximation of the actual rating assignment process, since ratings constitute the informed opinion of an analyst who assembles as much (macroeconomic) data as possible on a given country and consequently forms an opinion on the risk of insolvency of this country. As a last step, the analyst must transform this judgement into a rating scales. Thus the first two steps of this process are captured by equation (1). $X_{i, t}$ represents the data assembled on the country at hand, whereas the $Y_{i, t}^{*}$ is the actual decision on the risk of insolvency of the country. The process of transforming this decision into a rating is represented by equation (3). Therefore, one needs a statistical method that accounts for this framework. The obvious choice for this setting is a binary or ordered choice model in the form of a logit or a probit regression.

This paper makes use of both types of regressions. The binary choice regression is employed to model the rating changes of countries. When doing this, one must split the rating change sample into upgrades and downgrades, otherwise the regression would identify rating changes into different directions as rating changes in the same direction. Additionally, the splitting gives the opportunity to investigate asymmetries between upgrades and downgrades. Another advantage of a binary choice regression is that specifying a dynamic model is much less troublesome for the binary case compared to the ordered case. A detailed explanation for this can be found in section 2.2. The disadvantage of using a binary regression is that it comes with the implicit assumption that rating changes are done indiscriminate of whether a country gets downgraded from AA to $\mathrm{A}$, or from $\mathrm{C}$ to default. Also, one has to realize that a series with upgrades as well as downgrades might be problematic due to the fact that there is asymmetric movement in the regressors, compared to the dependent variable. For example, when analyzing upgrades there is a distinct time span when upgrades are relatively sparse, however, downgrades are relatively frequent. In this period, the regressor variables are moving in line with the downgrades, but the binary upgrade series does not exhibit any change. This might lead to a distortion in the regression.

An ordered probit is employed when analyzing the actual ratings. Ratings are an example of an ordered series, as triple A clearly is better than $\mathrm{BB}+$. One of the advantages of this approach is that, unlike the binary approach, it makes use of all information contained in the rating data, since now we have the level of the rating available.

\subsection{Model and Dynamic Specification}

In this section a dynamic specification for probit regressions is developed. Consider:

$$
Y_{i, t}^{*}=X_{i, t-1} \beta^{\prime}+E_{i, t},
$$

where $Y_{i, t}$ is a measure of the rating or rating change or a rating level, $X_{i, t-1}$ is a set of regressors, and $E_{i, t}$ are the errors. To specify a model with dynamics for a binary choice case one can simply set up a regression including a variable of autoregressive order one, that is I simply lag the rating change and use it as an explanatory variable. This allows to investigate whether the CRAs are taking past rating history into account, that is whether ratings are path-dependent or not. This is similar to the rating stickiness documented by Ferri et al. (1999), and it is interesting to see whether this extends to European countries as well. De Jong and Woutersen (2011) show the validity of the Maximum Likelihood approach for a dynamic setting. It should be noted that a coefficient bigger than one does not imply nonstationarity or an explosive process, due to the fact that in order to be interpretable it needs to be evaluated by using 
equations (??) or equation (??).

This straightforward approach unfortunately does not work for the ordered probit regression. Generally, in order to safely qualify for an autoregression, the ordered variable should be interval scaled. This is clearly not the case for the rating series at hand. Also, when actually estimating, the dynamic ordered probit exhibit massive problems to converge. Therefore, I follow a different approach when specifying a dynamic model for an ordered probit, building on the work of Kauppi and Saikkonen (2008). They propose to include a lagged probability of the dependent variable as additional regressor such that:

$$
\pi_{t}=\Phi\left(X_{i, t} \beta^{\prime}\right),
$$

where $\Phi($.$) is the cumulative normal distribution. In this case I follow the method employed by Candelon$ et al. (2010), estimating the lagged probability in a first step regression by using Ordinary Least Squares for the following equation:

$$
\ddot{Y}_{i, t}=X_{i, t-1} \beta^{\prime}+E_{i, t},
$$

where $\ddot{Y}_{i, t}$ is the demeaned version of the rating data. For this method to yield actual probabilities, start by determining $\Phi\left(X_{i, t} \beta^{\prime}\right)$, which creates the probability $\pi_{i, t}$. As a second step one introduces $\pi_{i, t-1}$ into the ordered probit as an additional regressor, thereby estimating a dynamic model. Furthermore this approach must be used in some cases for the dynamic binary probit estimations, instead of relying on the simple autoregressive approach, due to the breakdown of the MLE when dealing with a regressor which predicts the independent variable perfectly, which is the case in some of the estimations. However, a word of caution needs to be added here since this method is only an imperfect proxy for the autoregressive process, because the regressions only partly explain the variation in the dependent variable and therefore the lagged probability given by these estimations can also only partly model the true dynamics.

One last remark about the overall approach of using a simple pooled panel approach is in order. Generally introducing dynamics into a probit model is as also shown by the preceding paragraphs not completely straightforward. Additionally, asymptotic behavior for most binary or ordered choice model is only known when the cross section grows, which is not the case for this dataset. Therefore, it was decided to go with the simplest model, in order to bypass most of the problems involved when estimating a more complex model.

\section{Empirics}

\subsection{Data}

This paper employs quarterly data retrieved from Eurostat. The series start in the first quarter of 2001 and end in the last quarter of 2010. It contains data from 21 EU countries, namely Belgium, Czech Republic, Denmark, Germany, Estonia, Ireland, Spain, France, Italy, Cyprus, Latvia, Lithuania, Luxembourg, Hungary, the Netherlands, Austria, Poland, Portugal, Slovenia, Finland, and the United Kingdom. ${ }^{1}$ The data set consists of the following variables: GDP per capita, GDP growth, inflation rate, government debt as percentage of GDP, net current account as percentage of GDP, and the primary balance as percentage of GDP. These variables were used in earlier studies such as Afonso et al. (2007) or Bennell et al. (2006) and found to be significant in explaining sovereign ratings. For the primary balance I have to interpolate for quarterly data, which was also the case for the current account for Belgium in the year of 2001. Using a Bry-Boschan algorithm as described in Bry and Boschan (1971) a

\footnotetext{
${ }^{1}$ Greece was excluded due to missing data
} 
business cycle indicator is created. This variable is set equal to one during a boom-time and equal to minus one in a recession. Furthermore there is a GIPS variable which indicates whether a country is part of the European troubled economies, that is it is equal to one in case of Spain, Ireland, Portugal, and Italy. Gärtner et al. (2011) finds a significant relationship between ratings and these countries. For the dependent variable, the respective ratings are Long Term: Issuer Rating (Foreign) from Moody's, Issuer Credit Rating Foreign Long Term by Standard and Poor's, and Long Term Issuer Default Rating by Fitch. These are all the equivalent of a long term default assessment. These ratings are transformed into two different scales. First, there is a binary rating-event series where a one corresponds to a rating change and a zero to no change in rating in the respective quarter. Separate series for upgrades and for downgrades are constructed. Second, I transfer all rating data into a numerical scale according to the following table: Multiple rating events in one quarter are treated differently for each series. The purpose

Table 2: Rating Scale Part 1

\begin{tabular}{cccc}
\hline Numerical & Moody's & S \& P & Fitch \\
\hline 22 & Aaa & AAA & AAA \\
21 & Aa1 & AA+ & AA+ \\
20 & Aa2 & AA & AA \\
19 & Aa3 & AA- & AA- \\
18 & A1 & A+ & A+ \\
17 & A2 & A & A \\
16 & A3 & A- & A- \\
15 & Baa1 & BBB+ & BBB+ \\
14 & Baa2 & BBB & BBB \\
13 & Baa3 & BBB- & BBB- \\
12 & Ba1 & BB+ & BB+ \\
\hline
\end{tabular}

Table 3: Rating Scale Part 2

\begin{tabular}{cccc}
\hline Numerical & Moody's & S \& P & Fitch \\
\hline 11 & Ba2 & BB & BB \\
10 & Ba3 & BB- & BB- \\
9 & B1 & B+ & B+ \\
8 & B2 & B & B \\
7 & B3 & B- & B- \\
6 & Caa1 & CCC+ & - \\
5 & Caa2 & CCC & CCC \\
4 & Caa3 & CCC- & - \\
3 & Ca & CC & CC \\
2 & Ca & C & C \\
1 & C & D & D \\
\hline
\end{tabular}

of the first series is to separate quarters with a rating event from quarters without one. Thus multiple rating changes except for the first one are ignored. For the numerical scale, a two-notch downgrade is completely reflected in the data, the only problem present is that one cannot distinguish between a two notch downgrade at one date and two single rating changes within a given quarter. However, the latter is seldom the case in the investigated time span. Furthermore a pooled version for the ratings is constructed, by averaging all three series and rounding mathematically.

\subsection{Preliminary Tests}

Before starting with the actual estimations some preliminary tests need to be conducted. I start with a test for cross sectional dependence. Cross sectional dependence (CD) means that there is a correlation structure between different countries. This is often the case for country panels, since countries, especially in close geographic proximity, are often highly dependent on each other. Estimation-wise, this will lead to distorted standard errors as well as biases in dynamic models. For the CD-test every regression specification used in the paper is estimated and the corresponding test developed by Hsiao et al. (2012) is used. ${ }^{2}$ It looks at the average correlation between the generalized residuals introduced by Gourieroux et al. (1987) to investigate whether there is a systematic relationship in the cross sectional dimension. The results can be found in table 4 . For simplicity, only the binary regressions are investigated. Only in one case is the null hypothesis of no cross sectional dependence rejected. Therefore, it is concluded that no systematic cross sectional dependence is present in the dataset. A possible reason is for not detecting

\footnotetext{
${ }^{2}$ Please note that instead of using individual regressions, a pooled version is employed due to the invariancy of the dependent variable for some elements of the cross section.
} 
cross sectional dependency could be the rather short time-dimension of our dataset which is merely a decade long.

Table 4: Cross Sectional Dependence Test

\begin{tabular}{ccccc}
\hline & $\begin{array}{c}\text { static } \\
\text { upgrades }\end{array}$ & $\begin{array}{c}\text { static } \\
\text { downgrades }\end{array}$ & $\begin{array}{c}\text { dynamic } \\
\text { upgrades }\end{array}$ & $\begin{array}{c}\text { dynamic } \\
\text { downgrades }\end{array}$ \\
\hline pooled & 0.349 & 1.649 & 0.387 & 1.812 \\
critical value at 5\% & $(4.748)$ & $(2.947)$ & $(4.732)$ & $(2.780)$ \\
Moody's & 4.800 & 2.567 & 1.229 & 2.651 \\
critical value at 5\% & $(2.966)$ & $(4.646)$ & $(5.707)$ & $(4.717)$ \\
S \& P & 0.909 & 2.198 & 0.890 & 2.254 \\
critical value at 5\% & $(5.365)$ & $(4.874)$ & $(5.042)$ & $(4.861)$ \\
Fitch & 0.567 & 1.660 & 0.532 & 1.630 \\
critical value at 5\% & $(5.824)$ & $(4.886)$ & $(4.771)$ & $(5.084)$ \\
\hline
\end{tabular}

This means one can go ahead with the proposed estimation strategy and use standard probit to tackle the question at hand, instead of trying to correct for cross sectional correlation. This also means that established robust standard errors can be used. ${ }^{3}$

Also, a test for heteroskedasticity is conducted, which is on the one hand crucial for discrete response regressions, on the other hand not exactly straightforward as in the linear OLS case. The importance of this test lies in the fact that one assumption for identifying the parameters of a discrete response regression is a constant variance. Therefore, when having a case of heteroskedasticity not only are the estimates inconsistent but actually the point estimates make no sense at all (Wooldridge, 2001). However, the actual test is not simple because there are no clearly defined residuals for this regression-type, which we could inspect. Instead I reestimate each regression using a heteroskedasticity-robust probit method introduced by Harvey (1976) and conduct a Wald test for significance of the coefficient modeling the variance. Using this approach implies that variables that might model the variance need to be selected. There is no reason to suspect heteroskedastic errors in the ordered series, however for the binary series, the business cycle variable could have influence on the variance, since upgrades and downgrades are separated. For upgrades there is always more activity during boom times and for downgrades there is always more activity during a recession. The results of the test can be found in table 5; the null hypothesis of the Wald test is no heteroskedasticity.

Table 5: Heteroskedasticity Test for Binary Probit

\begin{tabular}{ccc}
\hline & upgrades & downgrades \\
\hline Pooled & 0.085 & 0.770 \\
Moody's & 0.379 & 0.014 \\
S \& P & 0.000 & 0.835 \\
Fitch & 0.000 & 0.572 \\
\hline
\end{tabular}

As it can be seen, there are three cases of heteroscedasticity present. In those cases the heteroskedastic probit regression introduced by Harvey (1976) is used. ${ }^{4}$

\footnotetext{
${ }^{3}$ It should be noted that the test based on Fitch's downgrades is the non-bootstrapped version of the test due to data difficulties with the bootstrapped sub-samples.

${ }^{4}$ Please note that Fitch was excluded from these preliminary tests, due to problems with the variable modeling the variance, for further details see table 9 and 11
} 


\subsection{Rating levels}

The first regression estimated is:

$$
\begin{aligned}
\text { rating }_{i, t} & =\beta_{0}+\beta_{1} \text { Debt }_{i, t-1}+\beta_{2} \text { inflation }_{i, t-1}+\beta_{3} \text { growt }_{i, t-1}+\beta_{4} \text { primarybalance }_{i, t-1} \\
& +\beta_{5} \text { currentaccount }_{i, t-1}+\beta_{6} \text { businesscycle }_{i, t-1} \\
& +\beta_{7} \text { GIPS } * \text { businesscycle }_{i, t-1}+\beta_{8} \text { GIPS }_{i, t-1}+\epsilon_{i, t}
\end{aligned}
$$

This is done for every rating agency separately as well as a fourth probit pooling the ratings by the average (rounded) rating assigned to the countries on the left hand side. This regression approach is essentially analyzing the rating level of each country. One could therefore expect that also only stock variables to be significant. However there is a considerable amount of literature for example Afonso (2003) or Gärtner et al. (2011) who find stock as well as flow variables to be significant in their regressions. Therefore both types of variables are used as regressors.

Table 6: Rating Level Estimations using Ordered Probit

\begin{tabular}{ccccc}
\hline & average rating & Moody's & S \& P & Fitch \\
\hline GDP & $3.607^{* * *}$ & $2.172^{* * *}$ & $4.596^{* * *}$ & $3.826^{* * *}$ \\
government debt & $(0.436)$ & $(0.466)$ & $(0.606)$ & $(0.500)$ \\
& $-0.029^{* * *}$ & $-0.018^{* * *}$ & $-0.037^{* * *}$ & $-0.028^{* * *}$ \\
inflation & $(0.005)$ & $(0.006)$ & $(0.006)$ & $(0.006)$ \\
& -0.013 & -0.007 & -0.029 & -0.024 \\
growth & $(0.017)$ & $(0.015)$ & $(0.018)$ & $(0.018)$ \\
& 0.021 & 0.017 & 0.025 & 0.034 \\
primary balance & $(0.026)$ & $(0.024)$ & $(0.039)$ & $(0.027)$ \\
& $0.118^{* *}$ & 0.080 & $0.140^{* * *}$ & $0.106^{* *}$ \\
current account & $(0.0471)$ & $(0.057)$ & $(0.037)$ & $(0.044)$ \\
& 1.275 & 0.583 & $3.063^{* * *}$ & 1.240 \\
business cycle & $(0.791)$ & $(1.250)$ & $(1.109)$ & $(0.944)$ \\
& $-0.242^{* * *}$ & $-0.213^{* * *}$ & -0.098 & $-0.189 * *$ \\
interaction & $(0.075)$ & $(0.077)$ & $(0.116)$ & $(0.082)$ \\
& $0.676^{*}$ & 0.462 & $0.592^{*}$ & 0.674 \\
GIPS & $(0.356)$ & $(0.318)$ & $(0.333)$ & $(0.442)$ \\
& 0.071 & 0.331 & -0.254 & 0.003 \\
& $(0.578)$ & $(0.575)$ & $(0.596)$ & $(0.588)$ \\
\hline R-squared & 0.395 & 0.270 & 0.474 & 0.410 \\
\hline Standard errors in all estimations are clustered robust &
\end{tabular}

Looking at the GDP variable in table 6, one can see that for all three agencies as well as the pooled rating the coefficients are significant and the sign is positive. This means that a higher output per capita increases the likelihood of a higher rating which makes economic sense. Turning to government debt, all coefficient signs are negative and in all four regressions the impact of government debt on ratings is statistically significant. This means that a higher indebtedness of the public sector increases the probability of a lower rating, keeping everything else constant. These findings are largely in line with Afonso et al. (2009), who studies ratings for a country panel involving developing nations as well as developed ones. In row three and four, inflation and the growth rate of GDP are both statistically not distinguishable from zero. This is contrary to the before mentioned paper that do find these variables to be statistically correlated to the level of rating, however it does make sense from an intuitive perspective that the level of rating should also only be connected to the level of the economic indicators. Some mixed signals are received when looking at the primary balance and the current account. Two individual 
CRA regression as well as the pooled regression exhibit a significant coefficient for the primary balance whose direction also makes sense from an economic perspective, a higher primary balance is associated with the probability of a higher assigned rating. The current account is only in the Standard and Poors regression significant, which hints towards the fact that overall, rating agencies do not see the trade balance as an important factor for determining the solvency of a country within the EU. This makes sense in sofar that EU countries normally can issue bonds in their own currency. Comparing this to developing countries who issue a significant amount of debt often in US Dollar, the latter need to have trade surpluses in order to service the non-home currency denominated debt. Thus we possibly see here a fundamental distinction between developing and developed countries. Lastly, there are in three cases negative significant coefficients for the business cycle variable as well two out of four positive significant coefficients for the interaction between the business cycle and the GIPS countries. The former indicates that CRAs are rating countercyclical, meaning that in boom times the probability of getting a higher ratings assigned are a bit lower than they should be, and in bad times the rating level is likely a bit higher. The positive sign of the interaction variable means that this effect is the opposite for the GIPS country group, hinting either towards discrimination or a fundamental difference between those countries and the rest of the sample. However, already giving a glimpse on the next results, these do not hold when taking dynamic behavior into account. Also, the R-squares are on the lower end of what is common in the literature, but given our much smaller dataset, this is not unexpected. Note that Moody's is a bit of an outlier with and R-square of only around 0.27 .

In table 7 , the following regression is estimated:

$$
\begin{aligned}
\text { rating }_{i, t} & =\beta_{0}+\beta_{1} \text { Debt }_{i, t-1}+\beta_{2} \text { inflation }_{i, t-1}+\beta_{3} \text { growt }_{i, t-1}+\beta_{4} \text { primarybalance }_{i, t-1} \\
& +\beta_{5} \text { currentaccount }_{i, t-1}+\beta_{6} \text { businesscycle }_{i, t-1} \\
& +\beta_{7} \text { GIPS } * \text { businesscycle }_{i, t-1}+\beta_{8} \text { GIPS }_{i, t-1}+\beta_{9} \text { estimatedprobability }_{i, t-1}+\epsilon_{i, t} .
\end{aligned}
$$

The main difference to the regression estimated for table 6 is the addition of a dynamic term which takes the form of an estimated probability as in equation 6. As already explained, this is similar to an autoregressive estimation, but tweaked to work well in an ordered probit setup. Comparing the results of the dynamic estimations with the static ones from table 6, one can see that GDP as well as government debt continue to play a significant role in explaining rating levels, and the magnitudes and signs are also similar. Also the flow variables, that is inflation and GDP growth are not statistically significant, except for inflation in the regression on $\mathrm{S} \& \mathrm{P}$ ratings. In this case, a higher inflation rate is increasing the probability to have a lower rating, which seems reasonable, since higher inflation is often connected to an increasingly unstable economic situation. The primary balance is now only significant for the Standard and Poors regression, so is is the current account balance. Again both coefficient signs make economic sense, a higher primary balance is connected to a higher rating level, the same logic applies to the current account. When now looking at the business cycle, the GIPS indicator and the interaction between these two, none of them are significant anymore. Instead these effects are most likely picked up by the dynamic variable. The interpretation of this variable is that given that one has a high rating, it is also more likely to stay in that rating. This relationship is also true for a low rating, thereby leaving more countries with a lower rating, than they would actually deserve, given the economic fundamentals. The R-squares remain largely unchanged compared to the static regression. This is an example of path dependency, that is rating agencies are taking the rating history into account instead of just assigning ratings based on macroeconomic factors. 
Table 7: Dynamic Rating Level Estimations using Ordered Probit

\begin{tabular}{ccccc}
\hline- & average rating & Moody's & S \& P & Fitch \\
\hline GDP & $2.499^{* * *}$ & $1.354^{* *}$ & $3.431^{* * *}$ & $2.809^{* * *}$ \\
government debt & $(0.613)$ & $(0.653)$ & $(0.578)$ & $(0.512)$ \\
& $-0.029^{* * *}$ & $-0.017^{* * *}$ & $-0.038^{* * *}$ & $-0.030^{* * *}$ \\
inflation & $(0.005)$ & $(0.005)$ & $(0.006)$ & $(0.007)$ \\
& -0.013 & -0.007 & $-0.028^{*}$ & -0.024 \\
growth & $(0.015)$ & $(0.014)$ & $(0.016)$ & $(0.017)$ \\
& 0.006 & 0.010 & 0.006 & 0.020 \\
primary balance & $(0.027)$ & $(0.022)$ & $(0.037)$ & $(0.026)$ \\
& 0.066 & 0.034 & $0.091^{* *}$ & 0.065 \\
current account & $(0.056)$ & $(0.074)$ & $(0.046)$ & $(0.054)$ \\
business cycle & 0.640 & 0.150 & $2.357^{* *}$ & 0.663 \\
interaction & $(0.847)$ & $(1.175)$ & $(1.106)$ & $(0.862)$ \\
& -0.088 & -0.096 & 0.052 & -0.045 \\
GIPS & $(0.091)$ & $(0.122)$ & $(0.087)$ & $(0.089)$ \\
& 0.463 & 0.328 & 0.392 & 0.478 \\
dynamics & $(0.421)$ & $(0.352)$ & $(0.383)$ & $(0.519)$ \\
& 0.144 & 0.227 & -0.054 & 0.058 \\
R-squared & $(0.634)$ & $(0.622)$ & $(0.652)$ & $(0.657)$ \\
& $2.140 * * *$ & 1.656 & $2.205^{* * *}$ & $1.934^{* * *}$ \\
\hline Standard & $(0.738)$ & $(1.441)$ & $(0.814)$ & $(0.663)$ \\
\hline
\end{tabular}

\subsection{Rating Changes}

This section takes a look not at the level of the rating but at rating changes. So far this has not been done regularly in the literature. The main advantage is that a dynamic model can easily be specified without having to rely on the estimated probability procedure used for estimating rating levels. As a first step the following regression equations are estimated:

$$
\begin{aligned}
\text { ratingchange }_{i, t} & =\beta_{0}+\beta_{1} \text { Debt }_{i, t-1}+\beta_{2} \text { inflation }_{i, t-1}+\beta_{3} \text { growth }_{i, t-1}+\beta_{4} \text { primarybalance }_{i, t-1} \\
& +\beta_{5} \text { currentaccount }_{i, t-1}+\beta_{6} \text { businesscycle }_{i, t-1} \\
& +\beta_{7} \text { interaction }_{i, t-1}+\beta_{8} \text { GIP }_{i, t-1}+\epsilon_{i, t}
\end{aligned}
$$

When looking at table 8 we see that as hypothesized, for rating changes the main significant variables are changes or growth rates. Starting with government debt (a stock variable), only Moody's seem to take it into account, whereas in all other cases it is insignificant. The coefficient has the correct sign, that is a higher level of government debt is associated with an increased probability of getting a downgrade. Turning to inflation, it can be seen that it is significant in three out of four regressions. Also, the coefficient points into the right direction, meaning that a higher level of price changes is correlated with an increased probability of a downgrade. For the variables growth and primary balance,regressors are significant in all equations. Again, the signs of the variables make economic sense, an increased primary balance and increased GDP growth is connected to a decreased risk of getting downgraded. The same pattern holds for the current account variable, a higher current account is associated with a decreased downgrade risk. It should be noted that the magnitude of the current account is normally smaller than the other variables set in relation to GDP. Therefore, the coefficient also needs to be greater in magnitude in order to have a similar impact upon rating changes. This explains the relatively big current account coefficients. The S \& P regression has a significant business cycle variable, whose sign points towards 
Table 8: Downgrades Estimations using Binary Probit

\begin{tabular}{ccccc}
\hline & down all & down Moody's & down S \& P & down Fitch \\
\hline government debt & 0.006 & $0.015^{* * *}$ & 0.005 & 0.004 \\
& $(0.005)$ & $(0.005)$ & $(0.004)$ & $(0.005)$ \\
inflation & 0.051 & $0.071^{*}$ & $0.057^{* * *}$ & $0.059^{* *}$ \\
& $(0.033)$ & $(0.041)$ & $(0.016)$ & $(0.027)$ \\
growth & $-0.089^{* * *}$ & $-0.150^{* * *}$ & $-0.062^{*}$ & $-0.124^{* * *}$ \\
& $(0.027)$ & $(0.043)$ & $(0.032)$ & $(0.034)$ \\
primary balance & $-0.183^{* * *}$ & $-0.111^{* * *}$ & $-0.097^{* * *}$ & $-0.108^{* * *}$ \\
& $(0.042)$ & $(0.031)$ & $(0.021)$ & $(0.025)$ \\
current account & $-6.453^{* * *}$ & $-7.554^{* *}$ & $-5.353^{* * *}$ & $-4.855^{* * *}$ \\
& $(2.230)$ & $(3.070)$ & $(1.748)$ & $(1.727)$ \\
business cycle & -0.067 & -1.387 & $-0.210^{* *}$ & 0.276 \\
& $(0.128)$ & $(0.910)$ & $(0.0958)$ & $(0.342)$ \\
interaction & $0.563^{* *}$ & $0.700^{*}$ & 0.309 & 0.344 \\
GIPS & $(0.219)$ & $(0.395)$ & $(0.191)$ & $(0.362)$ \\
& -0.052 & -0.496 & 0.236 & -0.012 \\
Constant & $(0.365)$ & $(0.682)$ & $(0.254)$ & $(0.453)$ \\
& $-2.890^{* * *}$ & $-4.644^{* * *}$ & $-2.895^{* * *}$ & $-3.143^{* * *}$ \\
R-squared & $(0.364)$ & $(0.829)$ & $(0.259)$ & $(0.497)$ \\
\hline
\end{tabular}

Standard errors in all estimations are clustered robust, a heteroskedastic probit regression was used for Moody's

procyclicality. That is, in an economic downturn is the chance of a downgrade increased, although the regression already takes the reduced economic activity via the growth variable into account. Contrary to that, in two regressions the interaction variable between the GIPS countries and the business cycle is positive significant, which means that the GIPS countries have a decreased chance of downgrades in bad times and an increased chance of downgrades in boom times. The GIPS variable itself is insignificant in every regression, which is different from Gärtner et al. (2011), however Gärtner only looks at levels of ratings. The R-squares are on a similar level as the ones explaining the rating level. Note that there is no R-square for the Moody's regression due to the non-definable R-square for the heteroskedastic probit, since the model just including the intercept also by definition already has a variable in it, thereby no longer being able to serve as baseline.

The estimations for upgrades are displayed in table 9. In this case government debt is significant for the pooled regression as well as the Standard and Poor's regression. Also the economic growth variable is significant in three out of four cases. In all significant cases point the coefficients into the right direction, that is a higher government debt is associated with a decreased chance for an upgrade and a higher growth-rate means a higher chance of getting upgraded. Contrary to the downgrade case inflation is insignificant in two of the four estimations. The primary balance is insignificant for all regressions. For the current account, one can see that it is significant in two cases, however the sign of the coefficient points into the wrong direction, actually meaning that an increase in the current account decreases the chances of an upgrade, which does not make much sense from an economic perspective. The business cycle regressor is relevant in the pooled estimations as well as in the Standard and Poor's regression. In the pooled cases it gives rise to a procyclical interpretation, that is a decreased chance of getting upgrade in economic boom times and an increased chance of upgrades in a recession, whereas for the $\mathrm{S} \& \mathrm{P}$ regression it is the opposite. Finally, the interaction variable as well as the GIPS variable are statistically significant in two cases. The interaction variable indicates that GIPS-countries upgrades have a more procyclical component in the Moody's regression, compared to the rest of Europe, and a more countercyclical component in the Fitch regression. The negative coefficient for the GIPS variable 
Table 9: Upgrades Estimations using Binary Probit

\begin{tabular}{ccccc}
\hline & up & up Moody's & up S \& P & up Fitch \\
\hline government debt & $-0.008^{*}$ & 0.001 & $-0.032^{* * *}$ & -0.005 \\
& $(0.005)$ & $(-0.004)$ & $(0.008)$ & $(0.011)$ \\
inflation & -0.032 & -0.004 & $-0.046^{* * *}$ & $-0.010^{*}$ \\
& $(0.021)$ & $(0.022)$ & $(0.023)$ & $(0.059)$ \\
growth & $0.052^{* *}$ & $0.079^{* * *}$ & 0.024 & $0.016^{* * *}$ \\
& $(0.024)$ & $(0.022)$ & $(0.019)$ & $(0.050)$ \\
primary balance & 0.005 & -0.003 & 0.016 & 0.019 \\
current account & $(0.027)$ & $(0.041)$ & $(0.077)$ & $(0.073)$ \\
& $-2.039^{*}$ & -1.724 & $-4.456^{* * *}$ & -3.592 \\
business cycle & $(1.043)$ & $(1.292)$ & $(2.256)$ & $(2.400)$ \\
& $0.239^{*}$ & -0.130 & $-1.333^{* * *}$ & - \\
interaction & $(0.138)$ & $(0.134)$ & $(0.405)$ & - \\
& - & $1.736^{* * *}$ & 0.338 & $-0.682^{* * *}$ \\
GIPS & - & $(0.188)$ & $(0.280)$ & $(0.357)$ \\
Constant & -0.214 & $-1.810^{* * *}$ & $-0.657^{* * *}$ & -0.016 \\
& $(0.226)$ & $(0.206)$ & $(0.237)$ & $(0.379)$ \\
& $-1.513^{* * *}$ & $-2.343^{* * *}$ & $-1.996^{* * *}$ & $-4.313^{* * *}$ \\
R-squared & $(0.255)$ & $(0.255)$ & $(0.419)$ & $(0.572)$ \\
\hline
\end{tabular}

Standard errors in all estimations are clustered robust, Fitch lacks the business cycle variable due to perfect failure prediction, the pooled estimations lack the interaction term due to non-concavity of the log-likelihood, the heteroskedastic probit was used for S \& $\mathrm{P}$ as well as Fitch

means that an upgrade is less likely for such a country. Does this mean that the CRAs are discriminating against the GIPS countries? I propose to look at the results with caution, since the explanatory power is rather low, and the results might be due to the very distinct downgrade environment in the last two years. Therefore, one should take a look and split the sample in 2007, before the financial crisis, to get a better idea from where these results are coming. This is done in the robustness section.

For the dynamic regression the following equation is estimated:

$$
\begin{aligned}
\text { ratingchange }_{i, t} & =\beta_{0}+\beta_{1} \text { Debt }_{i, t-1}+\beta_{2} \text { inflation }_{i, t-1}+\beta_{3} \text { growt }_{i, t-1}+\beta_{4} \text { primarybalance }_{i, t-1} \\
& +\beta_{5} \text { currentaccount }_{i, t-1}+\beta_{6} \text { businesscycle }_{i, t-1} \\
& +\beta_{7} \text { GIPS } * \text { businesscycle }_{i, t-1}+\beta_{8} \text { GIP }_{i, t-1}+\beta_{9} \text { ratingchange }_{i, t-1}+\epsilon_{i, t}
\end{aligned}
$$

The results can be found in table 10. Comparing the dynamic estimations to the static estimations the control variables remain at large similar. Again, most of the flow variables are significant, while a majority of the stock variables have no influence. Also, the magnitude of the regressors are close to their respective counterparts from the static regression. The newly introduced feature for these estimates is the dynamic component in the model. Indeed, one can observe that in three out of four regressions, the dynamic component is significant, and it should further be noted that in the one regression where it is not significant, the lagged probability approach needed to be used, which might be a less than perfect proxy for an autoregressive estimation. The interpretation of the dynamic component in this case is the following. Given that a country was downgraded, there is an increased chance of getting downgraded in the next quarter, even if we account for economic factors where the latter should be the only variables driving the downgrade. This is an example of path dependency of ratings That means in this case past rating changes have a significant impact on current ratings changes.

Similar results as in the static upgrade section are found in table 11, which introduces dynamics into these 
Table 10: Downgrades Dynamic Estimations using Binary Probit

\begin{tabular}{ccccc}
\hline- & down & down Moody's & down S \& P & down Fitch \\
\hline government debt & 0.006 & $0.015^{* *}$ & 0.005 & 0.004 \\
& $(0.004)$ & $(0.005)$ & $(0.004)$ & $(0.005)$ \\
inflation & 0.044 & $0.078^{* *}$ & $0.050^{* * *}$ & 0.027 \\
& $(0.029)$ & $(0.037)$ & $(0.017)$ & $(0.024)$ \\
growth & $-0.074^{* * *}$ & $-0.13^{* * *}$ & $-0.053^{*}$ & $-0.085^{* * *}$ \\
& $(0.023)$ & $(0.046)$ & $(0.028)$ & $(0.028)$ \\
primary balance & $-0.150^{* * *}$ & $-0.101^{* * *}$ & $-0.066^{*}$ & 0.022 \\
e & $(0.034)$ & $(0.032)$ & $(0.037)$ & $(0.034)$ \\
current account & $-5.841^{* * *}$ & $-7.390^{* *}$ & $-5.309^{* * *}$ & $-4.694^{* * *}$ \\
& $(1.977)$ & $(3.025)$ & $(1.679)$ & $(1.573)$ \\
business cycle & -0.015 & -1.568 & $-0.210^{* *}$ & 0.264 \\
interaction & $(0.152)$ & $(1.021)$ & $(0.093)$ & $(0.318)$ \\
GIPS & $0.421^{* *}$ & 0.638 & $0.404^{* *}$ & $0.813^{* *}$ \\
& $(0.213)$ & $(0.409)$ & $(0.185)$ & $(0.414)$ \\
dynamics & -0.040 & -0.347 & 0.026 & $-1.061^{*}$ \\
& $(0.314)$ & $(0.673)$ & $(0.292)$ & $(0.596)$ \\
Constant & $0.854^{* * *}$ & $0.668^{*}$ & 9.391 & $41.750^{* * *}$ \\
& $(0.240)$ & $(0.352)$ & $(7.417)$ & $(13.320)$ \\
R-squared & $-2.866^{* * *}$ & $-4.810^{* * *}$ & $-7.648^{* *}$ & $-24.330^{* * *}$ \\
& $(0.297)$ & $(0.832)$ & $(3.689)$ & $(6.841)$ \\
\hline
\end{tabular}

Standard errors in all estimations are clustered robust, a heteroskedastic probit regression was used for Moody's, the lagged probability approach was used for Fitch as well as S \& P, due to perfect correlation with the dependent variable

Table 11: Upgrades Dynamic Estimations using Binary Probit

\begin{tabular}{ccccc}
\hline & up & up Moody's & up S \& P & up Fitch \\
\hline government debt & $-0.007^{*}$ & 0.001 & -0.014 & 0.000 \\
& $(0.004)$ & $(0.003)$ & $(0.009)$ & $(0.014)$ \\
inflation & -0.025 & -0.003 & -0.023 & -0.091 \\
& $(0.019)$ & $(0.021)$ & $(0.021)$ & $(0.061)$ \\
growth & $0.045^{* *}$ & $0.078^{* * *}$ & 0.020 & 0.088 \\
& $(0.022)$ & $(0.020)$ & $(0.034)$ & $(0.088)$ \\
primary balance & 0.001 & -0.003 & 0.011 & 0.016 \\
current account & $(0.028)$ & $(0.041)$ & $(0.029)$ & $(0.0815)$ \\
& $-1.794^{*}$ & -1.68 & $-2.032^{* *}$ & -2.441 \\
business cycle & $(0.973)$ & $(1.320)$ & $(0.862)$ & $(2.330)$ \\
interaction & $0.211^{*}$ & -0.129 & $0.266^{*}$ & - \\
GIPS & $(0.128)$ & $(0.133)$ & $(0.148)$ & - \\
& $1.599^{* * *}$ & $1.733^{* * *}$ & $1.507^{* * *}$ & $-0.838^{*}$ \\
dynamics & $(0.156)$ & $(0.189)$ & $(0.208)$ & $(0.462)$ \\
& $-1.745^{* * *}$ & $-1.803^{* * *}$ & $-1.637^{* * *}$ & 0.439 \\
Constant & $(0.181)$ & $(0.206)$ & $(0.184)$ & $(0.523)$ \\
& $0.782^{* * *}$ & 0.275 & -2.791 & 54.350 \\
R-squared & $(0.172)$ & $(0.353)$ & $(35.420)$ & $(63.770)$ \\
& $-1.633^{* * *}$ & $-2.354^{* * *}$ & -0.249 & -32.540 \\
& $(0.222)$ & $(0.254)$ & $(18.390)$ & $(33.010)$ \\
\hline
\end{tabular}

Standard errors in all estimations are clustered robust, Fitch lacks the business cycle variable due to perfect failure prediction, the heteroskedastic probit has been used for Fitch

estimations. ${ }^{5}$ Turning to the variables, except for economic growth there are no systematically significant

\footnotetext{
${ }^{5}$ The heteroskedastic probit was not used for Standard and Poor's estimation, because in this case the maximum likelihood algorithm did not converge.
} 
economic variables that explain upgrades. Otherwise all comments on individual variables from the nondynamic probit regression directly apply to the dynamic version as well. The newly introduced dynamic coefficient is contrary to the case of downgrade-regressions only in the pooled case significant. This adds to the evidence gathered from the non-dynamic estimations that in this framework explaining upgrades is extremely difficult. There are two possible explanations for that. First, the sample period is not suited to explaining upgrades. In this case the regressors are exhibiting strong downwards tendency in the last three years of the sample, which is the financial crisis, but are not accompanied by any movement in the dependent variable, possibly diluting the preciseness of the estimations. However, if this is the case, an ordered probit model, investigating rating changes as a variable taking values of -1 (for a downgrade), 0 (for no change), and 1 (for an upgrade) should do a very good job of explaining the overall variation. This has been done in the robustness section and it turns out that the proposed regression does not do a good job in explaining the rating change. Therefore, another possible conclusion is that at least part of the upgrades given in the time the sample is covering might have been given not on the basis of an unbiased risk assessment.

\subsection{Robustness Tests}

In this section robustness tests are conducted. Specifically, logit against probit specifications, institutional factors, as well as subsamples of the main results are under scrutiny.

\subsubsection{Testing Probit against Logit approach}

I start by testing whether a probit or logit specification is correct. The consequence of choosing the wrong specification results in inconsistent estimates. Unfortunately, to the best of the authors knowledge, there exists no test covering our approach in the literature. Therefore, I have estimated all (non-ordered) regressions with probit specifications as well as with logit specifications. When examining the standard errors, one can see no systematic difference between the estimates. ${ }^{6}$ Therefore the probit approach seems to be valid.

\subsubsection{Other factors influencing Sovereign Ratings}

Looking at the explained variation of our data, it might be the case that our statistics are lacking some fundamental variables to explain sovereign rating levels. Often mentioned possibilities are institutional variables such as effectiveness of the government or the ease of doing business. In fact, using long term ratings in this analysis, it makes very much sense to use these factors, since they should significantly determine the long run prosperity of a nation. To check this, the Worldwide Governance Indicators, supplied by the World Bank are used. Unfortunately this database has only been established in 1996 and furthermore the sampling frequency is on a yearly basis (and that only since 2002, beforehand being biyearly). However, up to the knowledge of the author, this is one of the most reliable database on this topic, and therefore, it is used for this robustness test. The ratings are converted into yearly ratings, by simply taking the rating of the fourth quarter, and I estimate an ordered probit with time series dimension of 9 (from 2002 till 2010) and cross sectional dimension of 21 countries with the following variables as regressors: Voice and Accountability, Government Effectiveness, Regulatory Quality, Rule of Law, and Control of Corruption. These regressions are estimated separately for every CRA. It turns out that all

\footnotetext{
${ }^{6}$ The logit estimates are available upon request.
} 
independent variables are insignificant at the $10 \%$ level. ${ }^{7}$ Therefore we conclude that institutional factors do not play a significant role when evaluating developed sovereign debtors.

\subsubsection{Rating Changes and Sub-sample 2007}

In this section I come back to the question about the validity of the upgrade results with respect to the financial crisis time frame. An ordered probit with the dependent variable defined as taking values of -1 (for a downgrade), 0 (for no change), and 1 (for an upgrade) is estimated. The results can be found in the appendix in table 12. Overall the performance of this model is not impressive, with very few significant variables and an R-square that is closer to the upgrade probit ones, than it is to the downgrade estimations. Therefore, the estimations obtained beforehand are not fundamentally distorted by the fact that the binary rating change series is asymmetric, but instead upgrades are indeed less well explained in our estimations than downgrades are. Additionally, in table 13 in the appendix the regression with upgrades as a dependent variable is re-estimated covering a time span from 2001 till 2007, thereby excluding the financial crisis. As one can see, the fundamental problems of explaining upgrades within the framework remains, even when excluding this period. Therefore, the results obtained beforehand are still valid.

\section{Conclusion}

In this paper I investigate the behavior of CRAs assessing sovereign solvency of European Nations. Probit regressions are used to investigate upgrades and downgrades. While controlling for typical macroeconomic variables (GDP growth, sovereign debt level and change, etc.) frequently used in the literature I come to the following results. There are a few cases when rating agencies take the business cycle into account, however there is no clear pattern identifiable. What is really interesting is that there is a dynamic element in the rating change, usually lead to an increased probability of rating changes in the future, given that there is a rating change happening now. This might lead to a vicious circle, where financially troubled economies are further downgraded, leading to a higher cost of borrowing which in turn leads to more financial distress. Also employing ordered probit regressions to analyze actual sovereign debt ratings, I find that while controlling for typical macroeconomic factors, CRAs take the rating history into account. These findings are robust to a number of specification tests. Due to the extensive impact these ratings have on capital allocation as well as sovereign budgets, the current overreliance on ratings needs to be addressed on an international as well as on a national regulatory basis.

${ }^{7}$ The estimates are available upon request. 


\section{References}

Afonso, A. (2003). Understanding the determinants of sovereign debt ratings: Evidence for the two leading agencies. Journal of Economics and Finance, 27(1):56-74.

Afonso, A., Gomes, P., and Rother, P. (2007). What'hides' behind sovereign debt ratings? ECB Working Paper No. 711.

Afonso, A., Gomes, P., and Rother, P. (2009). Ordered response models for sovereign debt ratings. Applied Economics Letters, 16(8):769-773.

Altman, E. and Rijken, H. (2004). How rating agencies achieve rating stability. Journal of Banking 8 Finance, 28(11):2679-2714.

Arezki, R., Candelon, B., and Sy, A. (2011). Sovereign rating news and financial markets spillovers: Evidence from the european debt crisis. IMF working papers, pages 1-27.

Bar-Isaac, H. and Shapiro, J. (2012). Ratings quality over the business cycle. Journal of Financial Economics.

Baum, C. F., Krpava, M., Schafer, D., and Stephan, A. (2013). Credit rating agency announcements and the eurozone sovereign debt crises. Discussion Papers, DIW Berlin.

Bennell, J., Crabbe, D., Thomas, S., and Gwilym, O. (2006). Modelling sovereign credit ratings: Neural networks versus ordered probit. Expert Systems with Applications, 30(3):415-425.

Berger, A. and Udell, G. (2004). The institutional memory hypothesis and the procyclicality of bank lending behavior. Journal of Financial Intermediation, 13(4):458-495.

Bernanke, B., Lown, C., and Friedman, B. (1991). The credit crunch. Brookings papers on economic activity, 1991(2):205-247.

Borio, C., Furfine, C., and Lowe, P. (2001). Procyclicality of the financial system and financial stability: issues and policy options background paper of the bis. BIS papers, 1:1-57.

Bry, G. and Boschan, C. (1971). Front matter to" cyclical analysis of time series: Selected procedures and computer programs".

Candelon, B., Dumitrescu, E., and Hurlin, C. (2010). Currency crises early warning systems: Why they should be dynamic. METEOR research memorandum.

De Jong, R. M. and Woutersen, T. (2011). Dynamic time series binary choice. Econometric Theory, $27(04): 673-702$.

Ferri, G., Liu, L., and Stiglitz, J. (1999). The procyclical role of rating agencies: Evidence from the east asian crisis. Economic Notes, 28(3):335-355.

Gande, A. and Parsley, D. (2010). Sovereign credit ratings, transparency and international portfolio flows. MPRA Paper.

Gärtner, M., Griesbach, B., and Jung, F. (2011). Pigs or lambs? the european sovereign debt crisis and the role of rating agencies. International Advances in Economic Research, pages 1-12.

Gourieroux, C., Monfort, A., Renault, E., and Trognon, A. (1987). Generalised residuals. Journal of Econometrics, 34(1-2):5-32. 
Harvey, A. (1976). Estimating regression models with multiplicative heteroscedasticity. Econometrica: Journal of the Econometric Society, pages 461-465.

Hsiao, C., Pesaran, M., and Pick, A. (2012). Diagnostic tests of cross-section independence for limited dependent variable panel data models*. Oxford Bulletin of Economics and Statistics.

Kauppi, H. and Saikkonen, P. (2008). Predicting us recessions with dynamic binary response models. The Review of Economics and Statistics, 90(4):777-791.

Lowe, P. (2002). Credit risk measurement and procyclicality. BIS working paper.

Wooldridge, J. (2001). Econometric analysis of cross section and panel data. MIT press. 


\section{Appendix}

Table 12: Ordered Probit estimation Rating Changes

\begin{tabular}{cc}
\hline & rating change \\
\hline GDP & $-0.465^{* * *}$ \\
& $(0.124)$ \\
government debt & $-0.00442^{*}$ \\
& $(0.00267)$ \\
inflation & -0.0476 \\
& $(0.0298)$ \\
growth & $0.0595^{* * *}$ \\
& $(0.0174)$ \\
primary balance & $0.108^{* * *}$ \\
& $(0.0294)$ \\
current account & 1.857 \\
& $(1.702)$ \\
business cycle & 0.168 \\
interaction & $(0.120)$ \\
& -0.252 \\
GIPS & $(0.189)$ \\
& 0.0275 \\
R-squared & $(0.233)$ \\
\hline
\end{tabular}

Standard errors in all estimations are clustered robust

Table 13: Upgrades Estimations using Binary Probit subsample until 2007

\begin{tabular}{ccccc}
\hline & up & up Moody's & up S \& P & up Fitch \\
\hline government debt & $-0.008^{*}$ & -0.002 & $-0.016^{* * *}$ & -0.001 \\
& $(0.003)$ & $(0.006)$ & $(0.007)$ & $(0.005)$ \\
inflation & -0.010 & 0.006 & 0.006 & -0.034 \\
& $(0.019)$ & $(0.021)$ & $(0.028)$ & $(0.029)$ \\
growth & 0.045 & 0.063 & 0.006 & 0.057 \\
& $(0.033)$ & $(0.049)$ & $(0.049)$ & $(0.043)$ \\
primary balance & -0.030 & -0.008 & 0.026 & -0.013 \\
& $(0.035)$ & $(0.056)$ & $(0.051)$ & $(0.043)$ \\
current account & -1.362 & 0.116 & $-2.076^{* *}$ & -1.980 \\
business cycle & $(1.350)$ & $(2.095)$ & $(1.774)$ & $(1.611)$ \\
& 0.067 & -0.155 & 0.041 & 1.948 \\
GIPS & $(0.181)$ & $(0.210)$ & $(0.254)$ & $(63.538)$ \\
& -0.081 & 0.142 & -0.008 & -0.268 \\
Constant & $(0.243)$ & $(0.358)$ & $(0.337)$ & $(0.319)$ \\
& $-1.295^{* * *}$ & $-2.017^{* * *}$ & $-1.454^{* * *}$ & -3.776 \\
R-squared & $(0.325)$ & $(0.456)$ & $(0.470)$ & $(63.542)$ \\
\hline
\end{tabular}

Standard errors in all estimations are retrieved from Hessian 